\title{
Digital Literacy Learning Model in Digital Era
}

\author{
Dyah Lyesmaya \\ Elementary School Teacher of Education Program \\ Universitas Muhammadiyah Sukabumi \\ Sukabumi, Indonesia \\ lyesmaya_dyah@ummi.ac.id
}

\begin{abstract}
The use and abuse of digital technology in teaching and learning become a necessity in digital era. The digital era challenges future teacher to use information technology in teaching and learning at school with creative and innovative ways. PGSD (Elementary School Teacher of Education) students should also have the ability of using technology with creative and innovative ways in their teaching competences. This article aimed to investigate how to develop digital literacy skill by Digital Learning model in the classroom. The Digital Learning Model must be done by finding, managing, processing and presenting data from digital information. This study used $R \& D$ design and the subject were 20 second grade students from PGSD FKIP UMMI academic year 2015/2016. Data were gathered through observation, questionnaires, and interviews. This study revealed that this learning model made learning more meaningful and improved communication skills on how to present data visually. Based on this study results, it is recommended for lecturers to use this learning model to improve digital literacy skill.
\end{abstract} \section{Model}

Keywords- Digital Literacy, Digital Skill, Learning

\section{INTRODUCTION}

The growth of media industry, both print and non-print media, increase the use and abuse of information technology. Nowadays, people are connected easily to each other and compete with a global market in digital ways. In this digital era, we have many opportunities in various fields. To deal with this era, the human resources should be prepared including through education. The survival skills for new generation are critical thinking and problem solving; collaboration across networks and leading by influence; agility and adaptability; initiative and enterpreneuralism; effective oral and written communication; accessing and analyzing information; and curiosity and imagination [1]. Thus, skills and abilities are also really needed for our future teacher. The implication is that they should be able to teach the subjects by digging information through observation, questioning, trial, processing the data or information, and presenting data or information, followed by analyzing, reasoning, concluding and creating. Based on these reasons, most of the educational process depends on the ability and awareness of literacy.
Although media literacy is used in many ways on different levels of education, the curricular approach is different due to schools mission. Lee and Tiande [2] in their research found that:

'media literacy is used in many ways by different stakeholders at national university and school levels. Although the media literacy program in study was initiated by the same university, the curricular approaches of the partnership schools are different due to the schools' varying missions.'

Literacy in the digital era is defined not only as the ability to write and read, but broadly, literacy will relate to the ability to think, learn, and analyze non-print (digital) media. Therefore, PGSD students, as future teachers in the digital era, should analyze digital media to understand and appreciate digital structure and effects. Besides, they need to realize that through digital media, the view even attitudes may change. People learn about uses, strategies, and values simultaneously and haphazardly [3]. We learn literacy informally in everyday lives and we do not follow any step by step pattern as in the school. Based on this background, in this study, PGSD students learnt to experience digital media by digital literacy learning model. It means that PGSD students use their experiences with media in or outside the classroom as a common experiential basis for classroom exploration.

\section{METHOD}

This study used R\&D (Research and Development) design by Borg \& Gall [4]. Several methods were used in implementing this research design. The methods are descriptive, evaluative, and experimental methods. Descriptive method was used in the initial study to collect data on existing conditions, including (1) the condition of products that already exist as a comparison or base material for the product to be developed, (2) the condition of the user such as teacher, principal, school and students, (3) the conditions of enabling and inhibiting factors including the human element, facilities, and infrastructure, management costs, and the environment. Evaluative method was used to evaluate the development of a test product. Experimental method was used in addition to the experimental group also in the control group. Selection of the experimental group and the control was done randomly. 
The study was conducted through the following three stages: (1) Preliminary study was an early stage or preparation for development. This stage consisted of three steps: (a) literature study (a study to learn concepts about the model that will be developed); (b) field survey (field survey conducted to collect data relating to the planning and implementation of learning digital literacy, especially with regard to the development of literacy skills); (c) drafting model (the models draft reviewed in a meeting, which was attended by experts in the field of curriculum and learning, language education, and elementary school teachers who are experienced. Based on input from the meeting, the research team revised a draft model and then duplicated it as needed); (2) The second step was preliminary field testing and main field testing. In this stage, the first step undertakes limited testing later trials more widely. Limited trials for testing conducted on a class of students. In this class, 20 students applied the experimental method (single one-shot case study). The researchers observed and noted all important things. Advantages and weaknesses, errors, or irregularities were committed by the lecturers at the time of application of learning models. Furthermore, the more extensive trial was conducted. At this stage, more research sample of 60 students in three classes $\mathrm{A}, \mathrm{B}$, and $\mathrm{C}$ were involved; (3) The last step was dissemination and implementation. The efficacy testing of the product was the testing phase of the product which was to test the digital literacy learning model as compared to the usual lesson. Testing was done by using a quasi-experiment method in the experimental group and the control group (pretest-posttest control group design). Product testing will be conducted at the research stage further in the second year.

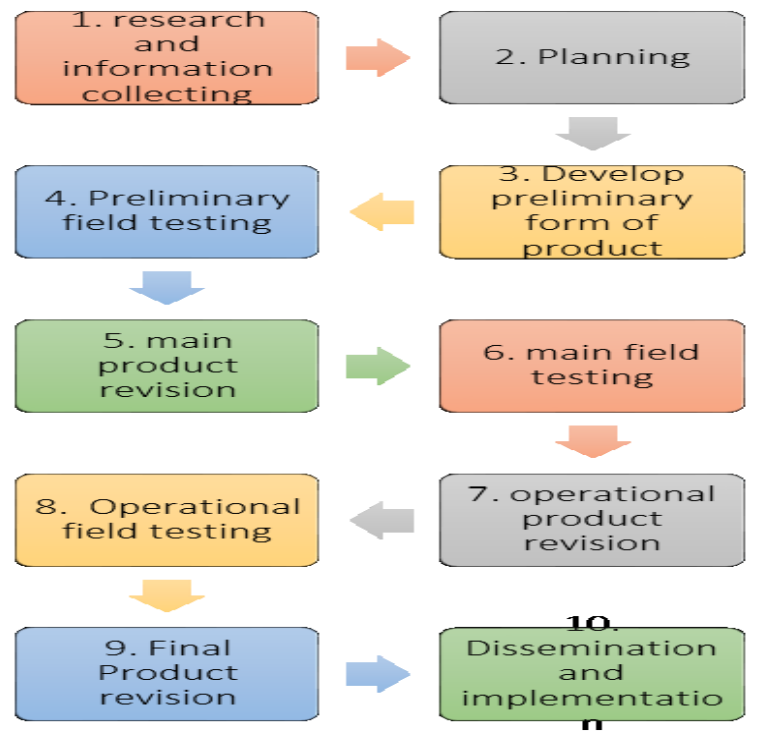

Fig 1. R\&D steps

The stages weredelivered in ten steps as follows: (1) research and information/data collecting; (2) planning and scheduled the research; (3) development of preliminary draft of product (the digital literacy learning model); (4) preliminary field testing on 20 PGSD students; (5) main product revision by a focus group discussion with expert; (6) main field testing;
(7) operational product revision; (8) operational field testing; (9) final product revision; (10) dissemination and implementation.

\section{RESULTS AND DISCUSSION}

Literacy means an ability to read and write and media means a communication tools [5]. These definitions build a meaning of media literacy. As Potter [6] said:

'media literacy is a set of perspectives that we actively use to expose ourselves to the media to interpret the leaning of the messages we encounter. We build our perspectives from knowledge structures. To build our knowledge structures, we need tools and raw material. These tools are our skills. The raw material is information from the media and from the real world. Active use means that we are aware of the messages and are consciously interacting with them.'

European commission [7] defines media literacy as follows:

'Media literacy may be as the ability to access, analyze and evaluate the power of image, sound, message, which we are now confronted with on daily basis and are on important part of our contemporary culture, as well as to communicate competently in media available on a personal basis.'

Based on those definitions about literacy and media literacy, we can conclude the definition of Digital Literacy as ability to access, analyze, and evaluate a digital media. In this research, to make PGSD students literate in digital media, they should be challenged to make their own digital media to deliver material in a classroom. Thus, they should: (1) understand and experience information literacy; (2) experience digital media; (3) create works in varied digital media so that they have direct knowledge of how to process and deliver information; (4) use varied digital media, in order to extend and express their understanding and feelings; (5) understand the process of creating within a given digital media through experience and practice with digital media making; (6) analyze their own transactions with media digital that they made; (7) analyze digital media their made to understand biases and values inherent in their media.

At the preliminary study, the researchers made preparations for the development of learning models. The preparation included studying the literature on digital-media learning and information Literacy, conducting a literature study regarding support skills using digital media, determining the subject of research, and conducting a field survey by interviewing digital media literacy.

From interviews, it is concluded that students know, understand, and use digital media in their daily lives. All PGSD students have not been involved in creating of print and non-print works previously. Supporting skills in the manufacture of media literacy were still not controlled. The 
supporting skills included the skills to operate a camera, computer software (Corel Draw, Photoshop, and WEB/Blog, etc.), writing skills with attention to the integration of scientific and skills of how to communicate through the media.

From the observation of the field testing, some findings were revealed. The subjects of the study had literacy skills in a medium stage. It meant that they were already fluent to use media, know the functions, carry out certain functions, and execute more complex operations. Digital media users can continue according to their need. The users knew how to obtain and assess information they needs, as well as using a strategy for specific information. Moreover, poor supporting skills produce digital media literacy. There were limited support tools, such as computer, smartphone, printers, and representative cameras. Poor Internet access on classroom was also the problem. Finally, the working team was not fully formed.

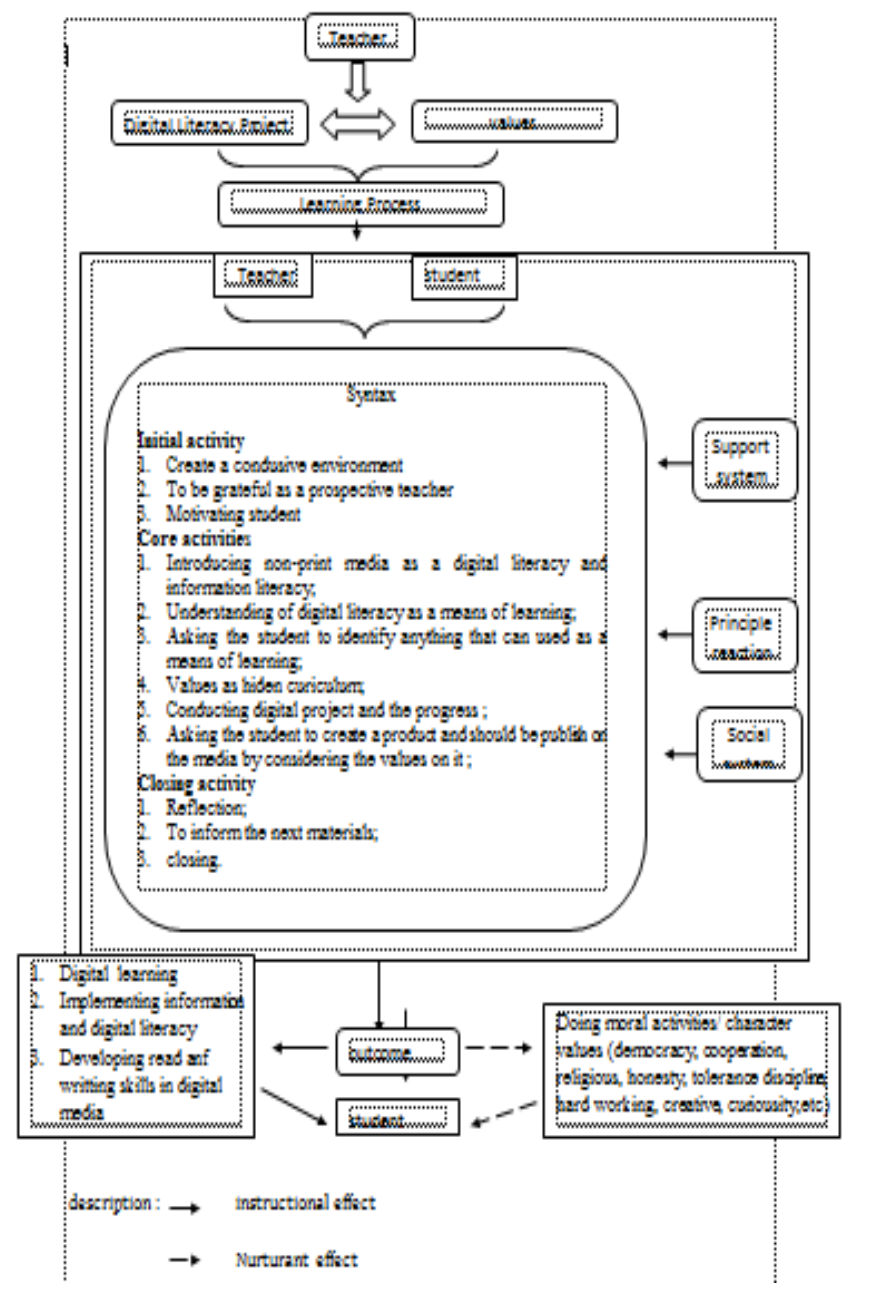

Fig 2. Digital literacy learning model

The models and its process drawn are as follows: (1). Preparation (student centered class discussion/ reflecting curiosity towards issues): (a) The students had a clear vision about the digital and information literacy; (b) The class was divided into two groups of digital literacy media (web and blogs); (c) The existing problems were explored by the students; (d) The problems were specified and considered in terms of what the values on it; (e) The information resources were estimated to collect data (interviewing, observe, book and internet); (f) The digital literacy project was planned (web and blog) and the class was divided into groups; (g) The courtesy was kept when collecting data or information; (h) A project journal was created that consisted of target activity, activity achievement, and the next activity. (2) Development (a groups discussion to formulated the project): (a) formulating problems they have to web/ blogs; (b) developing the tools of the project (ex: a draft of questionnaire); (c) recording obtained facts and data on to web/blogs; (d) checking the completeness and appropriates of the data with the goal of project; (e) processing on the result of the acquired data. (3) giving feedback (groups discussion to write down the project report): (a) writing down the report to web/blogs with the other groups as a reader target; (b) setting up the class for the reader circle (each group read the report of the other); (c) a group presentation; (d) giving tutors feedback (cross checking the aims of the project, the data completeness, the inserting values and the reader targets); (e) exchanging the draft report (to be evaluated by the other groups); (f). revising the draft 1; (g) tutors and teacher feedback; (h) revising the draft 2; (g) publishing; (4) reflection and conclusion: (a) reflecting all the observable processes by asking a question; (b) giving responses (by the student); (c) planning the next digital project.

\section{CONCLUSION}

Digital literacy learning model is an excellent approach to achieve national education goals. Digital literacy learning model emphasizes the creativity of learners. Lecturer task is to manage the class as a team that works together with students to find something new to the class (learners). Lecturers should manage boredom on learners themselves and revive motivation to learn them. The digital media can also be used as a tool to make the students understand or comprehend the material presented well, increase activity, and invite participation of learners in the learning interaction. Digital literacy learning activities in the classroom are implemented for achievement of learning itself. These activities are divided into classroom activities (classical activities), working in pairs (pair work), working group (group activities).

Digital literacy helps students to connect in the learning process. Students are trained to build their own knowledge of their active involvement in the learning process. Besides, the students are challenged to activate their metacognition skill through digital literacy skill. Reference [8] explains about metacognition as 'metacognition thus involves planning, monitoring, regulating, questioning, reflecting on and reviewing our cognitive processes.' The students become active learners in learning process. Their activities include of how to search, collect, analyze, and present data from digital media to audio and visual. 


\section{REFERENCES}

[1] W. Jhon, Research Design, Yogyakarta: Pustaka Pelajar, 2013

[2] Lee and Tiande, "Teaching and Learning Media Literacy in China: The Uses of Media Literacy Education," 2016. [Online]. Available: http://link.springer.com/chapter10.1007/978-981-10-0045-4 2\#page-1. [Accessed 222 2017].

[3] D. Borton, LITERACY, an Introduction The Ecology Of Written Language, USA: Lancaster University, 2007.
[4] Borg and Gall, Educational Research: an Introduction, New York: Routledge, 1989.

[5] Oxford, Oxford Dictionary, New York: Oxford University Perss, 1991.

[6] W. J. Potter, Media Literacy, New Jersey: Prentice Hall, 2005.

[7] E. Commossion, "Studi on Assessment Criteria for Media Literacy Level Brussel," 2009.

[8] K. L. Krause, S. Bochner and S. Duchesne, Educational Psychology for Learning and Teaching, Victoria: Thomson, 20013. 